\title{
Virtopsy-noninvasive detection of occult bone lesions in postmortem MRI: additional information for traffic accident reconstruction
}

\author{
Ursula Buck • Andreas Christe $\cdot$ Silvio Naether • \\ Steffen Ross $\cdot$ Michael J. Thali
}

Received: 12 June 2008 / Accepted: 31 October 2008 / Published online: 26 November 2008

(C) Springer-Verlag 2008

\begin{abstract}
In traffic accidents with pedestrians, cyclists or motorcyclists, patterned impact injuries as well as marks on clothes can be matched to the injury-causing vehicle structure in order to reconstruct the accident and identify the vehicle which has hit the person. Therefore, the differentiation of the primary impact injuries from other injuries is of great importance. Impact injuries can be identified on the external injuries of the skin, the injured subcutaneous and fat tissue, as well as the fractured bones. Another sign of impact is a bone bruise. The bone bruise, or occult bone lesion, means a bleeding in the subcortical bone marrow, which is presumed to be the result of micro-fractures of the medullar trabeculae. The aim of this study was to prove that bleeding in the subcortical bone marrow of the deceased can be detected using the postmortem noninvasive magnetic resonance imaging. This is demonstrated in five accident cases, four involving pedestrians and one a cyclist, where bone bruises were detected in different bones as a sign of impact occurring in the same location as the external and soft tissue impact injuries.
\end{abstract}

\footnotetext{
U. Buck $(\bowtie) \cdot A$. Christe $\cdot$ S. Naether $\cdot$ S. Ross $\cdot$ M. J. Thali Institute of Forensic Medicine, University of Bern,

IRM-Buehlstrasse 20,

CH-3012 Bern, Switzerland

e-mail: ursula.buck@irm.unibe.ch

U. Buck

State Police Bern, Accident Service,

Schermenweg 9,

3001 Bern, Switzerland

A. Christe

Institute of Diagnostic Radiology, University Hospital of Bern, 3010 Bern, Switzerland
}

Keywords Forensic radiology · Virtopsy · Bone bruise · Magnetic resonance imaging $\cdot$ Traffic accident reconstruction

\section{Introduction}

In the forensic investigation of traffic accidents, threedimensional methods are gaining in importance. In the Virtopsy research project at the Institute of Forensic Medicine of the University of Bern, radiological imaging techniques are used for the documentation and analysis of internal findings in addition to forensic medical examinations (http://www.virtopsy.com) [1, 2]. Highly precise 3D surface scanning is employed for the documentation of external body findings and of the involved vehicles [3-5].

For reconstruction purposes of pedestrian, cyclist or motorcyclist accidents, the internal and external impact injuries as well as the marks left on clothing are important indices for the investigation of the collision position $[6,7]$. The impact injuries caused by a car's front shock-absorbing structure are located mostly in the region of the lower extremities and depend on the size and posture of the struck person as well as on the shape of the car. If a wedge-shaped bending fracture of the long bone occurs, with convex fracture lines, a so-called Messerer wedge [8], the direction of the force effect can be determined by the basis of the shape of the fracture lines [9-11]. This can give clues for the impact position reconstruction. Another sign of impact on the bones of a deceased is a bone bruise. The bone bruise, or occult bone lesion, means bleeding in the subcortical bone marrow and is presumed to be the result of micro-fractures of the medullar trabeculae [12]. On macerated bones, a brownish discolouring of the bone is the indication of a bone bruise $[13,14]$. In clinical practice, the 

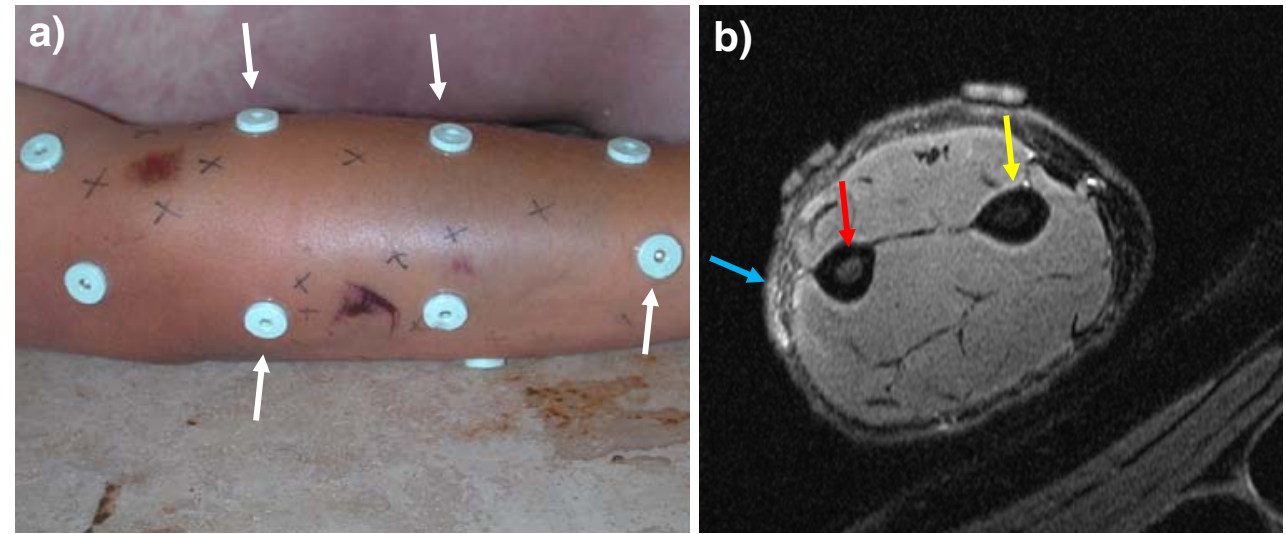

Fig. 1 Injuries on the right arm of a pedestrian who was hit by a motorbike (case 1). a Photograph of the external injury on the right forearm. The radiographic markers (white arrows) provide the fusion of the external and the internal dataset. b The axial MR image $\left(\mathrm{T}_{2} \mathrm{fs}\right)$

bone bruise is detected as signal intensity abnormalities in the magnetic resonance imaging (MRI).

The present study evaluated the method to detect these findings in bones of the deceased using postmortem MRI in a noninvasive manner and to use these findings as signs of impact.

\section{Materials and method}

The noninvasive detection of bleeding in the subcortical bone marrow was analysed and demonstrated in five cases.

The described cases are traffic accidents involving pedestrians and a cyclist, with impact injuries on the legs displaying a bleeding in the bone marrow of the ulna appeared as hyperintense signal alterations (red arrow). The radius showed a homogeneous dark signal (yellow arrow). Note the subjacent and intermuscular contusion on the same level (blue arrow)

or arms. The victims were between 7 and 84years old; one was female and the other four males.

As usual in the Virtopsy examination process, the internal findings were documented using both imaging modalities, whole-body multi-slice computed tomography (MSCT) and MRI. The patterned injuries on the skin as well as the inflicting vehicles were documented using a 3D optical surface scanner (TRITOP/ATOS 3D, GOM, Braunschweig, Germany). The high-resolution surface data produced are used for the comparison of the injuries with the injury-inflicting vehicle part and for the forensic reconstruction of traffic accidents $[2,5]$.

The MSCT examinations (Emotion 6, Siemens Medical, Erlangen, Germany) were performed with a
Fig. 2 Real data-based geometric reconstruction of the traffic accident (case 2). a High-resolution, true to scale and colour $3 \mathrm{D}$ model of the right upper arm. The red arrows show the superficial abrasion. b Due to the internal and external findings of the body and on the $3 \mathrm{D}$ model of the car, the impact position was reconstructed. The accident victim was kneeling on the ground when he was hit by the car
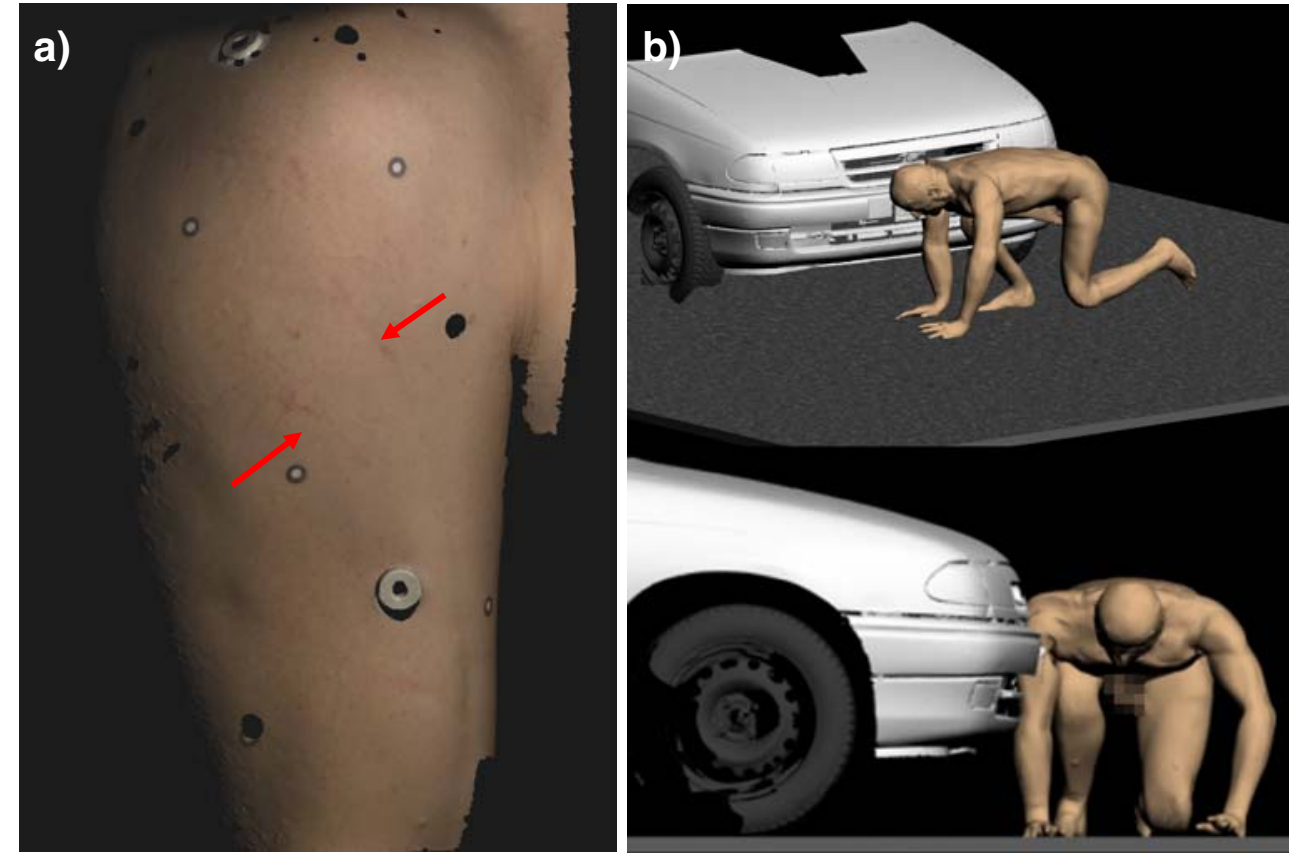
Fig. 3 Internal injuries of the humerus of a pedestrian who was hit by a car whilst kneeling on the ground (case 2). a The axial MR image $\left(\mathrm{T}_{2} \mathrm{fs}\right)$ displaying a bone bruise in the humerus appeared as hyperintense signal alterations (red arrow). b The T1-weighted sequence axial MR image displaying a bone bruise in the humerus appeared as hypointense signal alterations (red arrow)
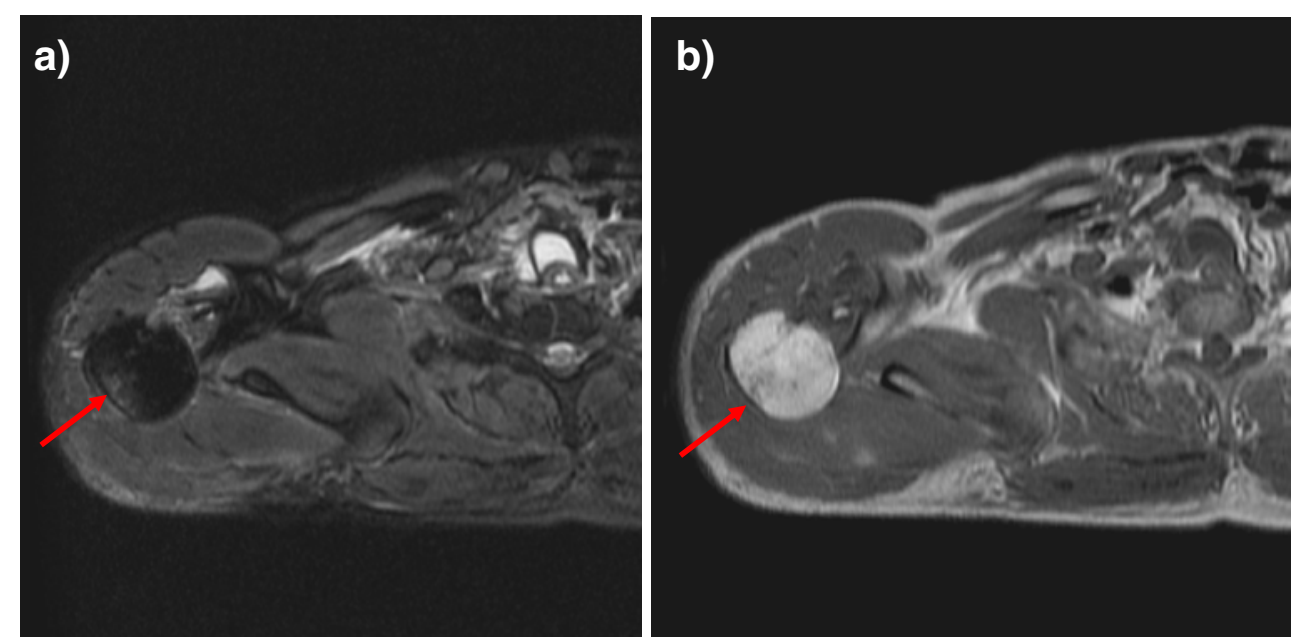

collimation of $6 \times 1 \mathrm{~mm}$ and a slice thickness of $1.25 \mathrm{~mm}$. For the areas of forensic importance, the MRI was performed with a 1.5-T system (GE $1.5 \mathrm{~T}$ Signa Echospeed Horizon, version 5.8; General Electric Systems, Milwaukee, WI, USA). For this MRI examination coronal, sagittal and axial images with weighting $\mathrm{T} 1$ and/or $\mathrm{T} 2$ fat saturation $\left(\mathrm{T}_{2} \mathrm{fs}\right)$ sequences were acquired. Imaging findings were evaluated by boardcertified radiologists, and traditional autopsies were
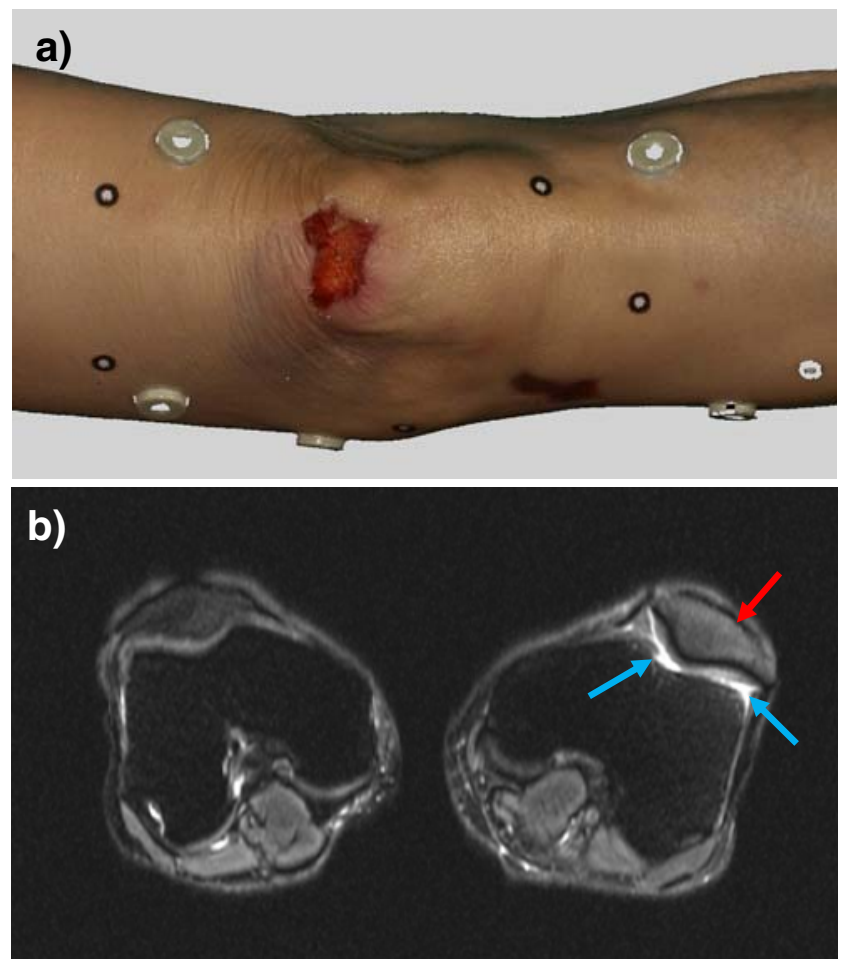

Fig. 4 Injuries on the left knee of a woman who was hit by a reversing car (case 3). a Coloured 3D model of the left knee was generated using the 3D photogrammetry and optical surface scanning. b The axial MR image ( $\mathrm{T}_{2} \mathrm{fs}$ ) displays a bone bruise in the patella (red arrow). Additional effusion in the knee joint is visible (blue arrows) performed by board-certified forensic pathologists in each case.

Radiographic markers (www.izimed.com) were stuck on the body for the fusion of the surface and radiological volume dataset (Fig. 1a).

In all cases, MSCT images were examined in order to establish whether the bones were fractured in the region of the soft tissue impact injuries. Fractured bones were not considered in this study.

The bones in the region of the soft tissue impact injuries in each case were examined in the T1-weighted and/or T2weighted fat saturation MR sequences. If hypo- (T1) and hyperintense (T2) signal alterations were present in the bone in the impact region, then this alluded to bleeding or oedema formation in the bone.

The bones without impact injury were examined in order to prove that they were homogeneous and that no signal alterations existed in the MR images.

\section{Results}

The bone bruises were detected in the MR images in the lower and upper extremities. In all cases, the CT images were examined in order to exclude existing bone fractures. In three cases, fractures of the long bones had occurred. The right femur in case 2 and the left tibia and fibula in case 4 were fractured, in case 5 the right fibula. The bone bruise was demonstrated in all cases in the locations where soft tissue impact injuries arose.

\section{Case 1}

A 21-year-old male died in the hospital after being hit by a motorbike whilst crossing the road as a pedestrian.

High intracranial pressure and brain oedema were considered as the cause of death. The impact injuries were located on the right side. 
Fig. 5 Considering all injuries and traces on the bicycle and car, the impact position was virtually reconstructed (case 4). The accident victim was riding the bicycle when he was struck by the car
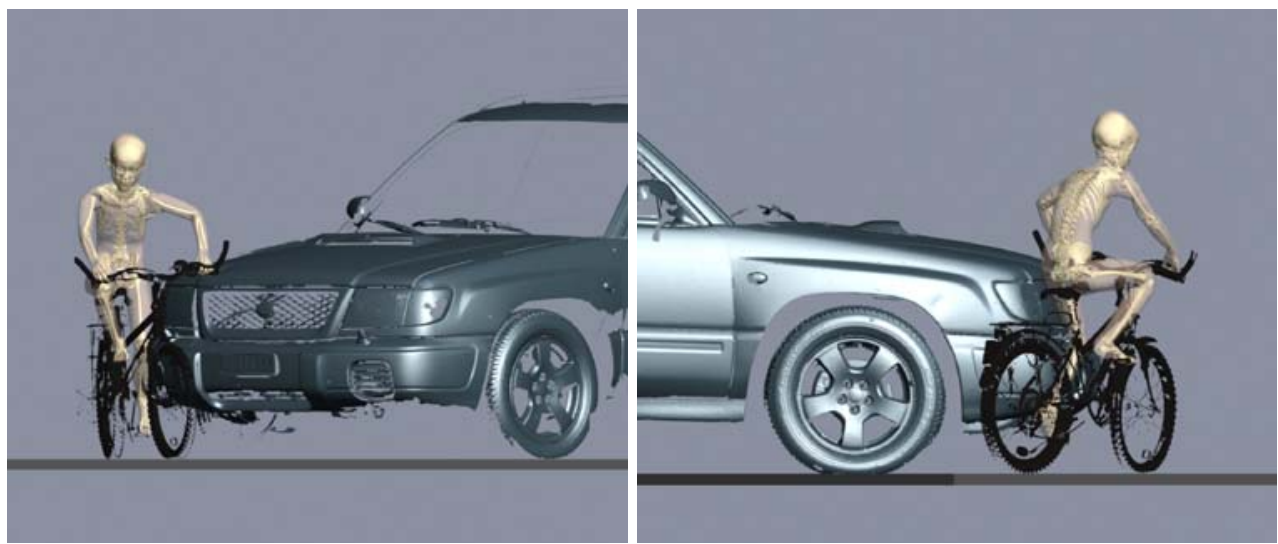

External injuries Patterned abrasion on the right forearm with subjacent contusion of the subcutaneous fatty tissue and musculature (Fig. 1a).

MRI The bleeding in the ulna appeared as hyperintense signal alterations in the $T_{2}$ fs (Fig. 1b).

\section{Case 2}

A 61-year-old male was fatally injured as a pedestrian in an accident with a car (Fig. 2b). Death occurred at the accident site due to blood aspiration in combination with severe loss of blood, pneumothorax and fat embolism. The body displayed collision injuries on the right leg and upper arm (Fig. 2a). Furthermore, there was an extensive trauma of the chest.

External injuries Contusion and suffusion of the fat tissue and musculature on the exterior upper right arm.
MRI The bone bruise in the humerus appeared as hypointense in the T1-weighted and hyperintense in the $T_{2} f s$ sequences (Fig. 3).

\section{Case 3}

A 74-year-old woman was hit by a reversing car. Death occurred at the accident site due to fat embolism and loss of blood. The impact injuries were located on the right side of the body.

On the exterior right hip and knee joint, there was a contusion of the subcutaneous fat tissue and musculature. Another subcutaneous haematoma was present in the region of the right elbow, and there was a deep abrasion on the left knee.

External injuries Subcutaneous haematoma on the area of the right elbow and deep abrasions on the left knee, medial (Fig. 4a).
Fig. 6 T2-weighted fat saturation sequence coronal MR images of both thighs of the cyclist (case 4). a The MR image displaying a bone bruise in the right femur appeared as hyperintense signal alterations (red arrow). b In the left femur, a bone bruise was also detected (red arrow)
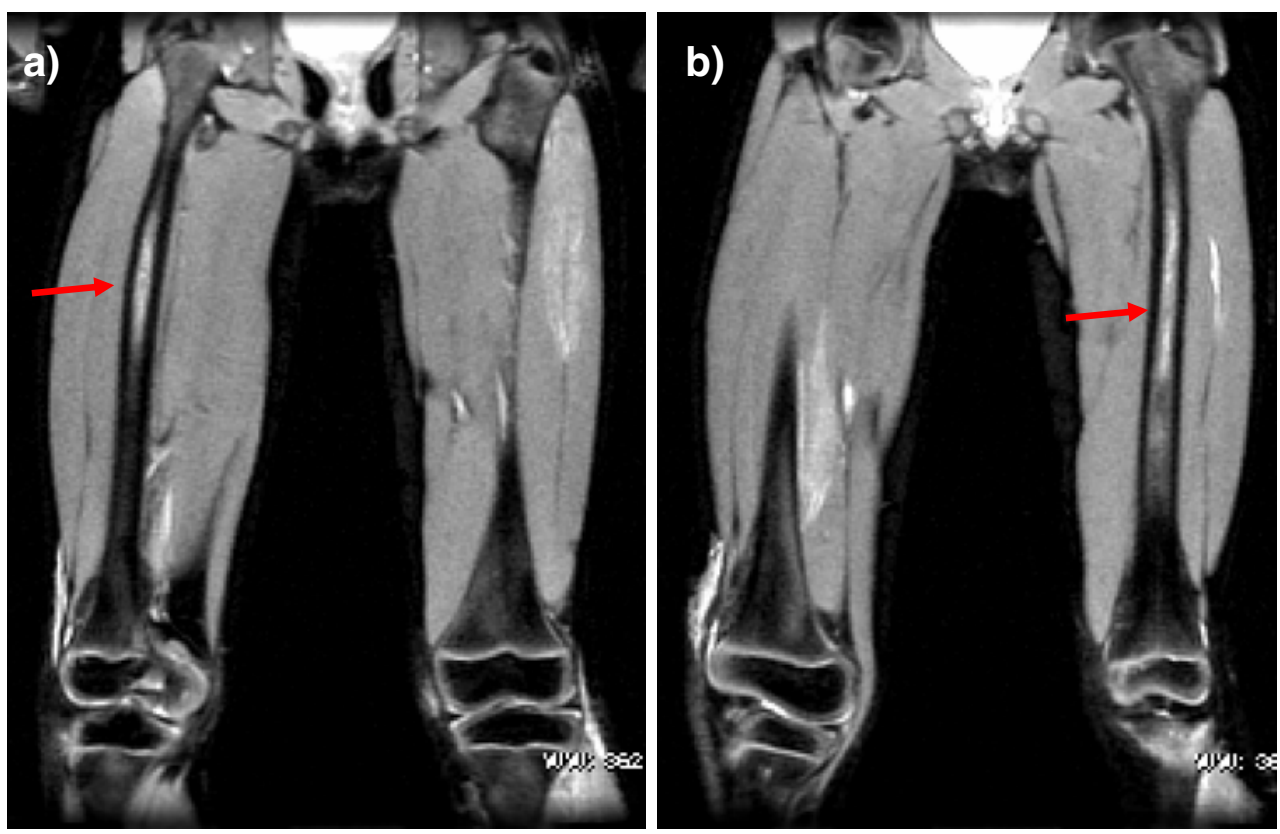
Fig. 7 Injuries of the right knee of a pedestrian who was hit by a car (case 5). a Suffusions with bruises over and under the patella of the right knee joint. b, c The T2-weighted fat saturation sequences axial MR images displaying a bone bruise in the tibia appeared as hyperintense signal alterations (red ellipse). Note the subcutaneous contusion adjacent to the bone bruise (blue arrows)
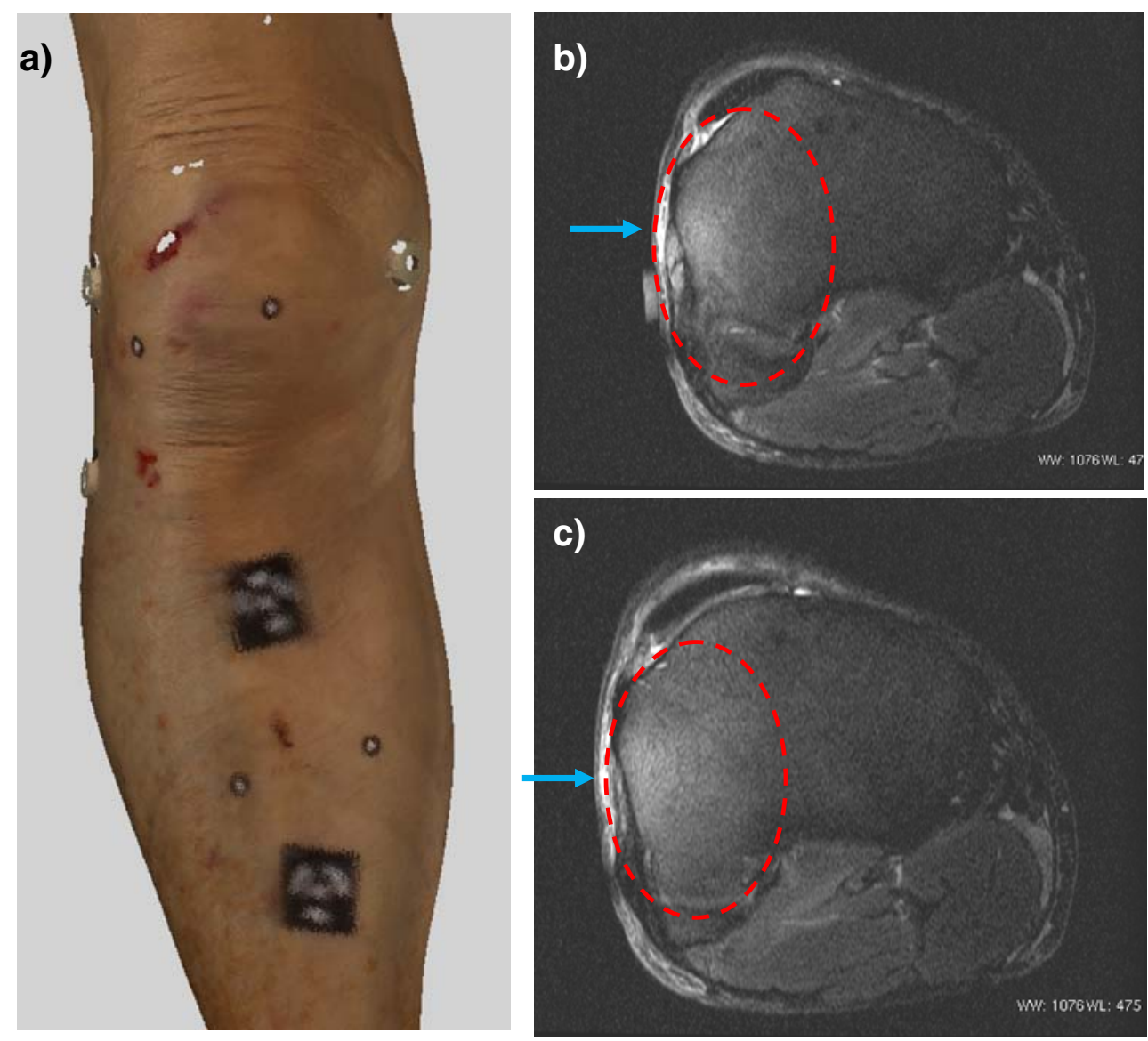

MRI Hyperintense signal alteration in the $\mathrm{T}_{2} \mathrm{fs}$ sequence indicating bone bruise in humerus and patella (Fig. 4b, c).

\section{Case 4}

A 7-year-old boy collided with a car whilst riding his bicycle (Fig. 5). He died several hours after the accident due to severe head trauma. Apart from cranial injuries, he also suffered several haematomas, bruises and a fracture of the left tibia and fibula.

External injuries Punctual haemorrhaging within the skin and a subjacent subcutaneous haematoma in the middle of both right and left thighs, frontal.

MRI The bone bruise in the subcortical bone marrow of the left and right femur appeared as hyperintense signal alterations in the $\mathrm{T}_{2}$ fs sequence (Fig. 6).

\section{Case 5}

An 84-year-old male was hit by a car while crossing a road behind a bus. Death occurred at the accident site due to fat embolism in combination with bleeding into the brainstem. In addition to a fatal head and thorax trauma, the victim displayed impact injuries on the right side of the body.

External injuries Many blue-red suffusions with bruises on the right leg around the patella on the right side of the knee joint (Fig. 7a).

MRI The bone bruise in the tibia appeared as hyperintense in the $\mathrm{T}_{2}$ fs sequence (Fig. $7 \mathrm{~b}, \mathrm{c}$ ).

\section{Discussion}

The study shows that the noninvasive radiological imaging methods are suitable for the detection of bone bruises in the subcortical bone marrow of the deceased. The bone bruises are visualised in the T1-weighted and T2-weigthed fat saturation sequences as abnormally low (T1) and abnormally high (T2 fat sat) signal intensities in the MR images. In all cases of studying different bones, bone bruises were detected in the location of the impact injuries.

In accidents with pedestrians, cyclists or motorcyclists, the correlation of the impact injury with the 
injury-causing vehicle parts is important in reconstructing the collision positions. Patterned impact injuries as well as marks on clothes can be matched to the injurycausing vehicle structure in order to reconstruct the accident and identify the vehicle. For this reconstruction purpose, it is necessary to differentiate the primary impact injuries from the other injuries of the deceased, which occurred for example by falling onto the road. The impact injuries can be identified on the external injury of the skin, the injured subcutaneous and fat tissue as well as in the fractured bones. The bone bruise is another important sign of an impact.

In contrast to the classical method of detecting bone bruising, with the maceration of the bones and the observation in the transmitted light to detect brownish discoloration in the bone or in the cut slices of the bone, the MRI method described is quicker, more practicable and is noninvasive.

All bones can be examined in the MR images in a short time in order to find bone bruises as a sign of impact for traffic accident reconstructions or for the investigation of unclear cases. In these unclear cases, the bone bruise is an important sign of force to the body. Bone bruises can also be detected in the bones of decomposed bodies.

In addition to the forensic medical examinations, postmortem imaging provides a noninvasive method of examining a body and supplying additional information for traffic accident analysis.

The advantages of a noninvasive, fast and observer independent postmortem documentation can be used for instance for purposes of forensic identification $[15,16]$ as well as for detection of bone bruises.

Furthermore, by knowing these postmortem findings, it is even possible to use whole-body MRI in clinical forensic medicine where noninvasive and non-radiation examination of a living accident victim and other living persons [17] is highly beneficial and especially when reconstructive questions are open.

Acknowledgements The authors thank Urs Koenigsdorfer and Roland Dorn for their help during the forensic examinations and Suzanne Horlacher, Elke Spielvogel, Karin Zwygart, Christoph Laeser and Carolina Dobrowolska (Department of Diagnostic Radiology and Neuroradiology, University of Bern) for the excellent help and data acquisition during the radiological examination. Many thanks also to Lowri Jones for her great support with linguistic knowledge.

\section{References}

1. Brogdon B (1998) Forensic radiology. CRC, Boca Raton

2. Thali MJ, Yen K, Schweitzer W et al (2003) Virtopsy, a new imaging horizon in forensic pathology: virtual autopsy by postmortem multislice computed tomography (MSCT) and magnetic resonance imaging (MRI) - a feasibility study. J Forensic Sci 48:386-403

3. Subke J, Wehner HD, Wehner F, Szczepaniak S (2000) Streifenlichttopometrie (SLT): a new method for the three-dimensional photoralistic forensic documentation in colour. Forensic Sci Int 113:289-295

4. Thali MJ, Braun M, Dirnhofer R (2003) Optical 3D surface digitizing in forensic medicine: 3D documentation of skin and bone injuries. Forensic Sci Int 137:203-208

5. Thali MJ, Braun M, Buck U et al (2005) Virtopsy-scientific documentation, reconstruction and animation in forensic: individual and real 3D data based geo-metric approach including optical body/object surface and radiological CT/MRI scanning. J Forensic Sci 50:428-424

6. Metter D (1983) Rechtsmedizinische Unfallrekonstruktion von tödlichen Fussgänger-PKW-Unfällen. Z Rechtsmed 91:21-23

7. Buck U, Naether S, Braun M et al (2007) Application of 3D documentation and geometric reconstruction methods in traffic accident analysis: With high resolution surface scanning, radiological MSCT/MRI scanning and real data based animation. Forensic Sci Int 170:20-28

8. Messerer O (1885) Über die gerichtlich-mediznische Bedeutung verschiedener Knochenbruchformen. Friedrich's Blätter für gerichtliche Medizin und Sanitätspolizei 36:81-104

9. Patschneider H (1963) Über Anprallverletzungen der unteren Gliedmassen bei Strasenverkehrsunfällen. Deutsche Zeitschrift für gerichtliche Medizin 54:336-366

10. Sellier K (1965) Zur Mechanik des Knochenbruchs. Deutsche Zeitschrift für gerichtliche Medizin 56:341-348

11. Mittmeyer HJ, König HG, Springer E, Staak M (1974) Die Unterschenkelfraktur verunglückter Fussgänger-Möglichkeiten und Grenzen der Unfallrekonstruktion. Z Rechtsmed 75:163-170

12. Boks SS, Vroegindeweij D, Koes BW, Hunink MGM, BiermaZeinstra SMA (2006) Follow-up of occult bone lesions detected at MR imaging: systematic review. Radiology 238:853-862

13. Lisowski Z, Marek Z (1982) Hyperpigmentation in the long bones of the lower limbs as a basis for vehicle identification and traffic accident reconstruction. Forensic Sci Int 20:251-255

14. Lisowski Z, Baran E, Marek Z (1981) Traumadiagnostik durch Untersuchung ungebrochener Knochen. Arch F Kriminol 167:110-116

15. Jackowski C, Wyss M, Persson A, Classens M, Thali MJ, Lussi A (2008) Ultra-high-resolution dual-source CT for forensic dental visualization-discrimination of ceramic and composite fillings. Int J Legal Med 122:301-307

16. Dedouit F, Telmon N, Costagliola R, Otal P, Florence LL, Joffre F, Rougé D (2007) New identification possibilities with post-mortem multislice computed tomography. Int J Legal Med 121:507-510

17. Yen K, Vock P, Christe A et al (2007) Clinical forensic radiology in strangulation victims: forensic expertise based on magnetic resonance imaging (MRI) findings. Int J Legal Med 121:115-123 